\title{
Patients' Priorities for Oral Anticoagulation Therapy in Non-valvular Atrial Fibrillation: a Multi-criteria Decision Analysis
}

\author{
Marieke G. M. Weernink ${ }^{1} \cdot$ Melissa C. W. Vaanholt ${ }^{1}$. Catharina G. M. Groothuis-Oudshoorn ${ }^{1}$. \\ Clemens von Birgelen $^{1,2} \cdot$ Maarten J. IJzerman ${ }^{1} \cdot$ Janine A. van Til $^{1}$
}

Published online: 22 August 2018

(c) The Author(s) 2018

\begin{abstract}
Introduction Effectiveness of oral anticoagulants (OACs) is critically dependent on patients' adherence to intake regimens. We studied the relative impact of attributes related to effectiveness, safety, convenience, and costs on the value of OAC therapy from the perspective of patients with non-valvular atrial fibrillation.

Methods Four attributes were identified by literature review and expert interviews: effectiveness (risk of ischemic stroke), safety (risk of major bleeding, minor bleeding, gastrointestinal complaints), convenience (intake frequency, diet restrictions, international normalized ratio [INR] blood monitoring, pill type/intake instructions), and out-of-pocket costs. Focus groups were held in Spain, Germany, France, Italy and the United Kingdom $(N=48)$ to elicit patients' preferences through the use of the analytical hierarchy process method.

Results Effectiveness (60\%) and side effects (27\%) have a higher impact on the perceived value of OACs than drug convenience $(7 \%)$ and out-of-pocket costs $(6 \%)$. As for convenience, eliminating monthly INR monitoring was given the highest priority (40\%), followed by reducing diet restrictions (27\%), reducing intake frequency (17\%) and improving the pill type/ intake instructions (15\%). The most important side effect was major bleeding $(75 \%)$, followed by minor bleeding $(15 \%)$ and gastrointestinal complaints (10\%). Furthermore, $71 \%$ of patients preferred once-daily intake to twice-daily intake.

Discussion Although the relative impact of convenience on therapy value is small, patients have different preferences for options within convenience criteria. Besides considerations on safety and effectiveness, physicians should also discuss attributes of convenience with patients, as it can be assumed that alignment to patient preferences in drug prescription and better patient education could result in higher adherence.
\end{abstract}

Electronic supplementary material The online version of this article (https://doi.org/10.1007/s40256-018-0293-0) contains supplementary material, which is available to authorized users.

Janine A. van Til

j.a.vantil@utwente.nl

1 Department of Health Technology and Services Research, Faculty of Behavioural, Management and Social Sciences, Technical Medical Centre, University of Twente, P.O. Box 217, 7500 AE Enschede, The Netherlands

2 Department of Cardiology, Thoraxcentrum Twente, Medisch Spectrum Twente, 7512 KZ Enschede, The Netherlands

\section{Key Points}

Effectiveness and safety are the most important attributes of oral anticoagulant (OAC) therapy.

Although the relative impact of convenience on therapy value is small, patients have different preferences for options within the convenience criteria.

It is recommended that besides considerations on safety and effectiveness, physicians also discuss attributes of convenience with patients. 


\section{Introduction}

Non-valvular atrial fibrillation (AF) is the most common heart rhythm disturbance encountered by physicians in clinical practice. AF is associated with a high risk of ischemic stroke and systemic embolism and increased mortality [1]. Vitamin K antagonists (VKAs) have been used as an effective oral anticoagulant (OAC) drug therapy to prevent AF-related stroke for many years [2]. Of these VKAs, warfarin is the most commonly used in clinical practice. More recently, the European Medicines Agency has approved a number of direct (non-VKA) oral anticoagulants (DOACs) [3]. Several randomized controlled trials and meta-analyses have shown that DOACs have a favorable risk-benefit profile when compared with warfarin [4-8]. DOACs reduce the risk in stroke, intracranial hemorrhage and mortality, with similar major bleeding rates as warfarin. However, DOACs can also result in an increased risk of gastrointestinal bleeding [5]. Overall, the relative efficacy and safety of DOACs are consistent across a wide range of patients [4]. The half-lives of DOACs are shorter than those of VKAs. Although this means that the anticoagulant effect of the drug is reversed sooner in case of emergency, it also means that its anticoagulation effect declines more rapidly with poor compliance compared to VKAs. Therefore, the effectiveness of DOACs is critically dependent on patient adherence to intake regimens.

In recent years, at least three conceptual models of adherence have been developed [9-11]. In these models, one determinant that is thought to influence adherence is drug convenience. DOACs have overcome some of the perceived inconveniences related to warfarin. For example, the stable therapeutic effect of DOACs (pharmacokinetics) does not require routine international normalized ratio (INR) monitoring. On the other hand, some DOACs have to be taken twice instead of once daily [12].

However, studies that focused on patient preferences found that drug efficacy and increased risk of bleeding were more important determinants of patient preferences for drugs compared to drug convenience [13-16]. Only when OACs have similar efficacy and safety rates, convenience attributes may matter to patients [12]. In addition, patient's adherence might be influenced by the convenience of the OAC therapy. An observational study found that reducing intake frequency from twice to once daily is associated with a $26 \%$ higher likelihood of adherence [17]. However, the actual impact of convenience on therapy adherence is still unclear. Given the high number of determinants of therapy adherence, it is difficult to determine relationships between these using traditional epidemiological research.

Therefore, the goal of this study was to gain more knowledge about the relative impact of attributes of therapy on the value of OAC therapy from the perspective of patients with AF. More specifically this study aimed to:

- Estimate the strength of preference of patients between criteria of convenience (e.g., intake once vs twice daily).

- Estimate the relative impact of attributes of convenience on overall convenience of OAC therapy (e.g., lower intake frequency vs no blood monitoring).

- Estimate the relative impact of drug convenience on the total value of OAC therapy, compared to other medication-related attributes (e.g., safety, effectiveness).

\section{Method}

The analytic hierarchy process (AHP) [18], a technique within the multi-criteria decision making (MCDM) methods, was used to rank and prioritize the attributes. MCDM methods allow for better structuring of the decision problem and are specifically helpful for people in making better choices that are consistent with their preferences and values $[19,20]$. AHP was originally developed in the $70 \mathrm{~s}$ and since then has been successfully applied to determine preferences for a variety of complex medical decisions [21, 22]. The first step of AHP is to decompose the criteria of the decision problem into a hierarchy of subcriteria, each of which can be analyzed independently. Subsequently, pairwise comparisons of (sub)criteria determine the relative importance of each criterion. An extensive description of all steps within AHP is presented in Hummel et al. [23].

\subsection{Developing the Value Tree}

A literature review was conducted in the PubMed and Scopus electronic databases to identify all possible criteria that affect the value of OACs among patients with AF. In total, seven groups of criteria were distinguished: biological effects (e.g., efficacy, safety); convenience (e.g., intake frequency, INR monitoring); healthcare organization (e.g., waiting time, out-of-pocket costs); knowledge and communication (e.g., information, patient involvement); social environment (e.g., social support, family); physical status (e.g., age, gender); and psychological status (e.g., anxiety, concern). More detailed information on the literature review can be found in Appendix 1 (see the electronic supplementary material). Next, eight key informants with expertise in the field of OAC therapy in patients with AF were asked to validate the results of the literature review. Experts were asked to complete a web-based survey in which they were questioned about the perceived impact of each criterion identified in the literature review. Subsequently, Skype interviews were held to discuss the responses in detail. Based on the literature review and the information obtained from key 
informants, the hierarchical value tree was developed by the project team (Fig. 1).

Criteria that were included in the AHP had to be characteristics that were modifiable, had to be relevant to patients and had to differ between the available OACs. Four main domains of criteria were selected: effectiveness, safety, convenience and out-of-pocket costs. These will be explained in detail below, along with the lower level dimensions. Literature showed that effectiveness is a main reason for patients to take OACs and therefore highly determines its value (10). Different definitions of effectiveness are used across studies, but we defined effectiveness as the ability of the OAC to reduce the risk of ischemic AF-related stroke. The safety domain includes the most common undesired adverse effects resulting from taking OACs, which are the risk of major bleeding, minor bleeding, and gastrointestinal complaints. Major bleeding was defined as significant blood loss that requires medical intervention, possible hospitalization, and blood transfusion. Minor bleeding might require medical attention, but is self-limiting and does not involve a critical site, such as, for instance, epistaxis (nose bleedings) [24]. Gastrointestinal complaints included dyspepsia, bloating, nausea, loss of appetite, and symptoms of feeling sick. Drug convenience highlights the degree to which a patient believes that taking an OAC will be free of effort [25]. Based on the interviews and literature [13, 14], we selected four criteria within the convenience domain: intake frequency, food restrictions, monthly INR monitoring, and pill type/intake instructions. The more often an OAC has to be taken each day, the more likely it is that patients forget to take it [17]. Intake frequency for OACs differs from taking a pill once or twice daily. Certain foods and beverages may interact with OACs, and therefore it is important to follow food restrictions and maintain a well-balanced and consistent diet. However, this can be bothersome and inconvenient. Additionally, some patients need to have their blood levels checked regularly to ensure that they are within the prescribed INR range to reduce the risk of clots or bleedings. They have to visit the clinic regularly or use a self-monitoring device, which can be inconvenient. The last subcriterion of convenience is the type of pill and associated intake instructions. It matters to patients whether they have to take a capsule or a tablet, whether the pill should be swallowed whole or can be taken with water or melts on the tongue, and whether it is required to take the pill with a proper meal. The fourth criterion is out-of-pocket costs, defined as the amount a patient has to co-pay for the OAC therapy each month (copayments, coinsurance, deductible). DOACs are more expensive than VKAs, and due to the need to economize expenses for healthcare, DOACs require higher out-ofpocket costs in some countries [26].

\subsection{Pairwise Comparisons}

After the main hierarchy and two subhierarchies were determined, the next step was to construct the pairwise comparisons in which patients would be systematically asked for the importance of each (sub)criterion. Each patient judges how important one criterion is compared to all other criteria, with respect to its (sub)hierarchy. In total, patients had to complete 15 pairwise comparisons to estimate criteria weights for all hierarchies. The judgment was made on a
Fig. 1 Value tree for selecting the optimal anticoagulant drug for AF-related stroke prevention. AF atrial fibrillation

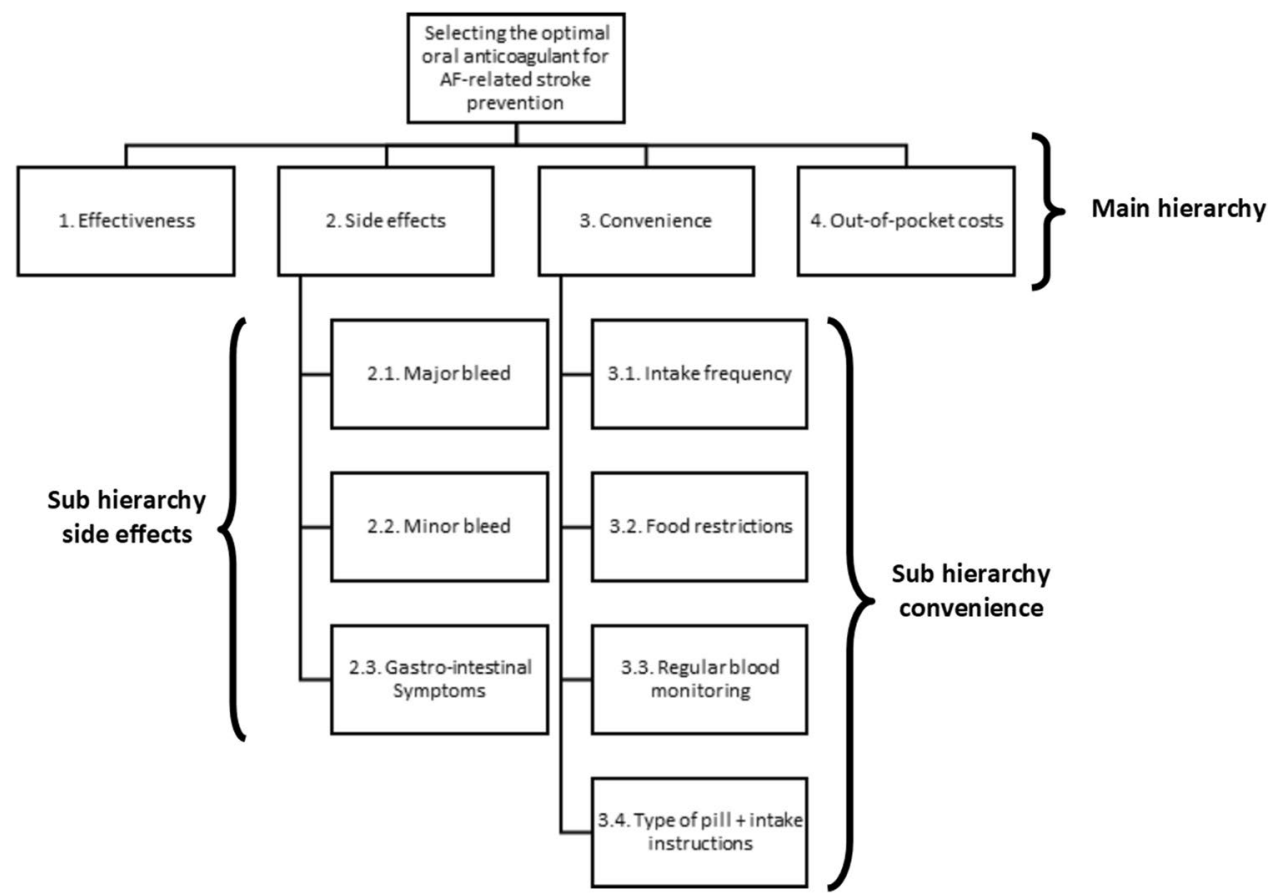


double 9-point scale, where 1 reflects equal importance and 9 reflects greater importance for one of the two criteria. An example of a pairwise comparison is shown in Fig. 2.

Furthermore, one of our specific aims was to estimate the strength of preference within the criteria of the convenience hierarchy (e.g., preference for once- or twice-daily intake). We used AHP pairwise comparisons to determine the performance of possible options within each subcriterion of convenience (Fig. 3). The different options which were compared to each other were intake frequency (once vs twice daily), food restrictions (yes vs no), and routine INR monitoring (yes vs no). Lastly, four different types of pills and related intake instructions were compared: (1) a capsule, swallowed whole, does not require intake with food; (2) a tablet, can be mixed with water, does not require intake with food; (3) a tablet, can be mixed with water, requires intake with food; and (4) a tablet which dissolves (melts) on the tongue and does not require intake with food. These four were selected based upon what is currently available on the market and possible future developments.

\subsection{Data Collection and Study Sample}

The AHP pairwise comparisons were questioned and discussed in 2-h focus group sessions with a convenience sample of patients with AF. To examine the European perspective, five sessions were conducted in France, Italy, Spain, the United Kingdom and Germany between 31 January 2017 and 15 February 2017. The size of focus groups should be determined based on the research aims [27], so we aimed to have ten participants in each focus group. This is large enough to generate enough discussion on medication adherence and retrieve AHP weights, yet small enough to have enough time to discuss all relevant topics.

A specialist recruitment agency (Lightspeed Research) recruited eligible patients via proprietary patient panels, local AF support groups and referral by healthcare professionals in hospitals or primary care settings. Patients were eligible if they were at least 18 years old, had a formal/an expert diagnosis of AF, were currently using OACs and were able to provide informed consent. All patients were paid $€ 90$ for participation in the study. Ethical approval of this study was obtained from the institutional review board of the University of Twente. All patients gave written informed consent, and all data were anonymized before analysis.

The 2-h focus groups were conducted by experienced moderators in the patients' native language and were taperecorded [28]. In the first hour, a qualitative discussion took place on patients' medication-taking behavior [29]. The second hour of the focus group was focused on determining the relative impact of the (sub)criteria of the value tree using the AHP pairwise comparisons and elicitation of performance weights. Patients received the answer form on paper, and the moderator introduced each group of pairwise comparisons (subhierarchies) separately. Prior to answering, the moderator explained all (sub)criteria in a general way (e.g., not mentioning specific effectiveness rates of available OACs) and asked whether all was clear. After each subsection was completed, the moderator asked whether some patients would like to explain their answers. Yet this was not done with the aim to reach consensus in the group, but to gather reasons for their choice behavior.
Fig. 2 Example of a pairwise comparison of two subcriteria of convenience rated on a preference scale (verbal comparison format)

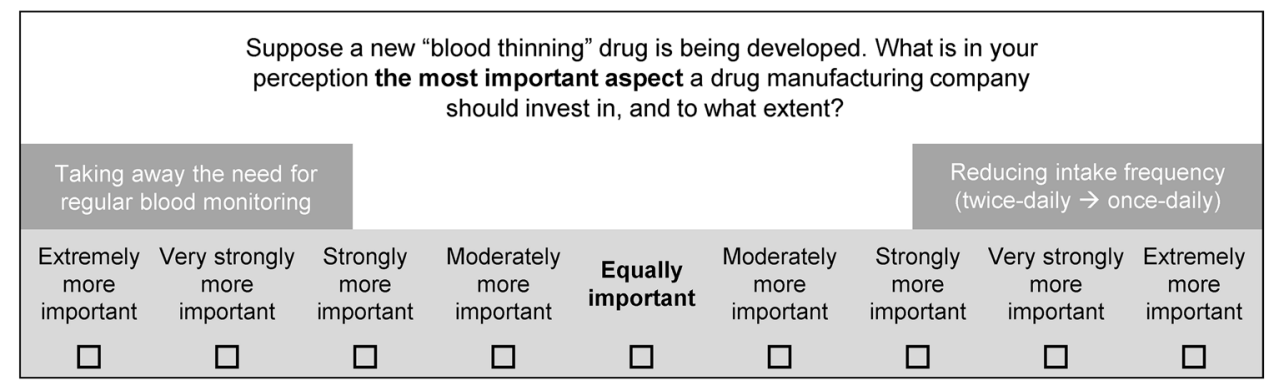

Fig. 3 Example of a pairwise comparison to determine the performance of two options of 'intake frequency' (verbal comparison format)

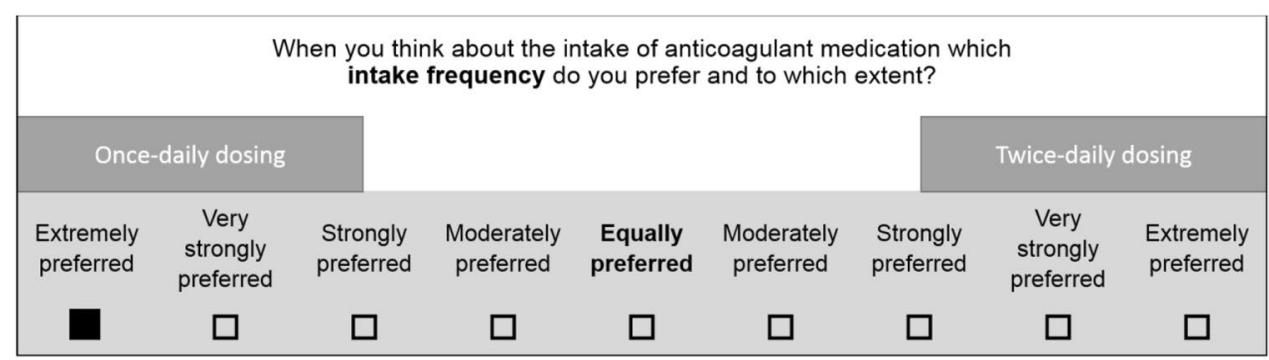




\subsection{Data Analysis}

First, the AHP pairwise comparisons are converted to the numeric scale and entered into a reciprocal matrix. There are two ways to aggregate individuals' judgments and priorities with the AHP [30]. In this research, we chose to combine individual judgments by taking the geometric mean and estimated priorities (criteria weights) from these judgments by computing the principle right-hand eigenvector. This method was chosen because it meets several required axiomatic conditions, such as the reciprocal property [30]. The criteria weights indicate their relative importance in the overall value of OAC therapy or one of the subhierarchies (convenience and side effects). The same method was also used to estimate the strength of preference (performance weights) for the options within the criteria of the convenience hierarchy (e.g., once- vs twice-daily intake). For both criteria and performance weights, bootstrap methods were used to obtain standard deviations. In addition, Chi square tests were used to study significant differences between patient's current and preferred options within convenience criteria. $P$ values lower than 0.05 were considered statistically significant.

Lastly, the comparison matrix of weights is used to calculate a measure of the consistency within each (sub)hierarchy of paired comparisons. This measure, called the inconsistency ratio, represents the ratio of the amount of inconsistency in patient's judgments in the pairwise comparisons. An inconsistency ratio of $<0.1$ is acceptable, indicating that conclusions from the AHP comparisons are mathematically sound. However, a consistency rate of $<0.2$ is generally accepted in individual preference-elicitation studies [23].

All analyses were performed using Microsoft Excel and IBM SPSS Statistics 24.0.

\section{Results}

\subsection{Respondent Sample}

In total, 48 patients participated in the focus groups. However, three patients (all from Italy) had multiple incoherent responses in their AHP pairwise comparisons and therefore were excluded from data analysis. The number of patients taking VKAs and DOACs across the sample was 58 versus $42 \%$. Other background characteristics of the patient sample can be found in Table 1 .

\subsection{Patient Preferences}

The results of our study indicate that patients attach most importance to high effectiveness of the OAC therapy (importance weight 0.60 ) (Table 2). The safety aspect of OAC therapy was the second-most important criterion (0.27). Within the subhierarchy of side effects, the most important side effect according to patients was major bleedings $(0.75)$, followed by minor bleedings (0.15) and gastrointestinal complaints $(0.10)$. The criteria convenience (0.07) and out-of-pocket costs $(0.06)$ were considered the least important according to patients. No notable differences in criteria weights were found for the different subgroups of patients receiving DOACs or VKAs.

Within the hierarchy of the convenience criterion, patients attached most importance to reducing the need for routine INR monitoring (0.40). However, when asked for a performance value on having or not having routine INR monitoring, about $40 \%$ of patients stated that they preferred to have routine INR monitoring and the same number of patients preferred not to have routine INR monitoring (Table 3). Eight patients (18\%) did not express a preference.

Subgroup analysis showed that the majority of patients on VKAs, who have INR monitoring, also prefer INR monitoring, and the majority of patients on DOACs, who do not have INR monitoring, also prefer this. However, there were also 12 patients that prefer the opposite of what they currently have.

Although the majority of patients (>75\%) were not bothered by possible food restrictions, reducing them was the second most important criterion which impacted the perceived convenience of OAC therapy (0.27). Patients on DOACs were more often bothered by possible food restrictions, but the difference with patients on VKAs was not statistically significant (32 vs $16 \%, P=0.22$ ).

Intake frequency had an impact of $17 \%$ on the perceived convenience of the drug, and the majority of patients (>70\%) preferred once-daily intake compared to twicedaily intake. Most patients currently take an anticoagulant with the intake frequency of their preference. However, the patients who currently take and prefer twice-daily intake assigned a performance weight of 0.54 to twice-daily intake, while the patients who currently take and prefer once-daily intake assigned a performance weight of 0.81 to once-daily intake.

With regard to preference for intake regimen, a tablet that can be mixed with water and does not have to be taken with food is preferred by most patients (36\%) (Table 3). Its average performance score was 0.33 . The tablet that dissolves (melts) on the tongue and does not require intake with food was preferred by $30 \%$ of patients and had an average performance score of 0.29. Least preferred was the OAC in the form of a capsule ( $9 \%$ of patients, performance score 0.13 ).

\section{Discussion}

The aim of the study was to elicit the patient perspective of the relative impact of attributes of convenience on the overall value of anticoagulants using a prescriptive 
Table 1 Socio-demographic and clinical characteristics of respondents across countries $(N=45)$. Data is reported as $n(\%)$ or mean \pm SD

\begin{tabular}{|c|c|c|c|c|c|c|}
\hline Variables & $\begin{array}{l}\text { Overall } \\
(n=45)\end{array}$ & $\begin{array}{l}\text { UK } \\
(n=10)\end{array}$ & $\begin{array}{l}\text { Germany } \\
(n=10)\end{array}$ & $\begin{array}{l}\text { France } \\
(n=8)\end{array}$ & $\begin{array}{l}\text { Spain } \\
(n=10)\end{array}$ & $\begin{array}{l}\text { Italy } \\
(n=7)\end{array}$ \\
\hline \multicolumn{7}{|l|}{ Gender } \\
\hline Man & $22(49.0)$ & $7(70.0)$ & $5(50.0)$ & $1(13.0)$ & $5(50.0)$ & $4(57.0)$ \\
\hline Woman & $23(51.0)$ & $3(30.0)$ & $5(50.0)$ & $7(87.0)$ & $5(50.0)$ & $3(43.0)$ \\
\hline \multicolumn{7}{|l|}{ Marital state } \\
\hline Yes & $33(73.0)$ & $9(90.0)$ & $6(60.0)$ & $5(63.0)$ & $6(60.0)$ & $7(100.0)$ \\
\hline No & $12(27.0)$ & $1(10.0)$ & $4(40.0)$ & $3(37.0)$ & $4(40.0)$ & - \\
\hline \multicolumn{7}{|l|}{ Age } \\
\hline Mean \pm SD & $62.3 \pm 13.2$ & $70.3 \pm 7.5$ & $60.3 \pm 10.5$ & $48.5 \pm 11.1$ & $71.1 \pm 11.8$ & $60.6 \pm 13.9$ \\
\hline Missing & & & & & $3(30.0)$ & \\
\hline \multicolumn{7}{|l|}{ Education level $^{\mathrm{a}}$} \\
\hline Low & $10(22.0)$ & $4(40.0)$ & - & - & $5(50.0)$ & $1(14.3)$ \\
\hline Medium & $10(22.0)$ & $2(20.0)$ & $3(30.0)$ & $3(37.5)$ & $1(10.0)$ & $3(42.9)$ \\
\hline High & $25(56.0)$ & $4(40.0)$ & $7(70.0)$ & $5(62.5)$ & $4(40.0)$ & $3(42.9)$ \\
\hline \multicolumn{7}{|l|}{ Employment status } \\
\hline Employed (full/part-time) & $3(6.7)$ & $3(30.0)$ & $5(50.0)$ & $7(87.5)$ & $3(30.0)$ & \\
\hline Retired & $20(44.4)$ & $7(70.0)$ & $4(40.0)$ & - & $5(50.0)$ & $3(42.9)$ \\
\hline Unemployed & $21(46.7)$ & - & $1(10.0)$ & $1(12.5)$ & $1(10.0)$ & $4(57.1)$ \\
\hline Missing & $1(2.2)$ & - & - & - & $1(10.0)$ & - \\
\hline \multicolumn{7}{|l|}{ Annual household income $(€)$} \\
\hline $0-15,000$ & $7(15.6)$ & $1(10.0)$ & $1(10.0)$ & $1(12.5)$ & $2(20.0)$ & $2(28.6)$ \\
\hline $15,001-25,000$ & $7(15.6)$ & - & $2(20.0)$ & $1(12.5)$ & $2(20.0)$ & $2(28.6)$ \\
\hline $25001-50,000$ & $12(26.7)$ & $5(50.0)$ & $3(30.0)$ & $1(12.5)$ & $2(20.0)$ & $1(14.3)$ \\
\hline $50,001+$ & $7(15.6)$ & $1(10.0)$ & $1(10.0)$ & $3(37.5)$ & $1(10.0)$ & $1(14.3)$ \\
\hline Unknown & $11(24.4)$ & $3(30.0)$ & $3(30.0)$ & $2(25.0)$ & $2(20.0)$ & $1(14.3)$ \\
\hline Missing & $1(2.2)$ & - & - & - & $1(10.0)$ & - \\
\hline \multicolumn{7}{|l|}{ OAC therapy } \\
\hline Total no. of patients on VKA & $26(57.8)$ & $6(60.0)$ & $6(60.0)$ & $4(50.0)$ & $5(50.0)$ & $5(71.4)$ \\
\hline Warfarin & $10(22.2)$ & $6(60.0)$ & - & - & - & $4(57.1)$ \\
\hline Acenocoumarol & $6(13.3)$ & - & - & - & $5(50.0)$ & $1(14.3)$ \\
\hline Phenprocoumon & $6(13.3)$ & - & $6(60.0)$ & - & - & - \\
\hline Fluindione & $4(8.9)$ & - & - & $4(50.0)$ & - & - \\
\hline Total no. of patients on DOAC & $19(42.2)$ & $4(40.0)$ & $4(40.0)$ & $4(50.0)$ & $5(50.0)$ & $2(28.6)$ \\
\hline Dabigatran & $7(15.6)$ & $1(10.0)$ & $3(30.0)$ & $1(12.5)$ & $1(10.0)$ & $1(14.3)$ \\
\hline Rivaroxaban & $7(15.6)$ & $1(10.0)$ & $1(10.0)$ & $2(35.0)$ & $3(30.0)$ & - \\
\hline Apixaban & $5(11.1)$ & $2(20.0)$ & - & $1(12.5)$ & $1(10.0)$ & $1(14.3)$ \\
\hline \multicolumn{7}{|l|}{ Time period on OAC therapy } \\
\hline$<1$ year & $19(42.2)$ & $5(50.0)$ & $1(10.0)$ & $4(50.0)$ & $3(30.0)$ & $6(85.7)$ \\
\hline $1-5$ years & $9(20.0)$ & - & $6(60.0)$ & $3(37.5)$ & - & - \\
\hline$>5$ years & $15(33.3)$ & $4(40.0)$ & $3(30.0)$ & $1(12.5)$ & $6(60.0)$ & $1(14.3)$ \\
\hline Missing & $2(4.4)$ & $1(10.0)$ & - & - & $1(10.0)$ & - \\
\hline
\end{tabular}

$D O A C$ direct (non-VKA) oral anticoagulant, $O A C$ oral anticoagulant, $S D$ standard deviation, $V K A$ vitamin $\mathrm{K}$ antagonist

${ }^{a}$ Low educational level: lower technical and vocational training and lower general secondary education; medium educational level: intermediate vocational training and advanced secondary education; high educational level: higher vocational education and university

multi-criteria decision model. The results of the study indicate that patients clearly prioritize the effectiveness and side effects of OACs (safety profile), and that convenience and out-of-pocket costs only have a minor impact on drug value. These findings are in accordance with the results of other studies, which found that the most important characteristics of therapy to patients are the effectiveness and side effects of the drugs [13-15]. 
Table 2 Importance weights for the criteria and subcriteria, reported as weight (standard deviation)

\begin{tabular}{llll}
\hline Attributes & All patients & VKA users & DOAC users \\
\hline Main dimensions & $N=44$ & $N=25$ & $N=19$ \\
Effectiveness & $0.60(0.02)$ & $0.58(0.03)$ & $0.64(0.02)$ \\
Safety (side effects) & $0.27(0.02)$ & $0.28(0.03)$ & $0.25(0.02)$ \\
Convenience & $0.07(0.01)$ & $0.08(0.01)$ & $0.06(0.01)$ \\
Out-of-pocket cost & $0.06(0.01)$ & $0.06(0.01)$ & $0.06(0.01)$ \\
Consistency ratio & 0.16 & 0.18 & 0.15 \\
Safety & $N=45$ & $N=26$ & $N=19$ \\
Major bleedings & $0.75(0.02)$ & $0.76(0.02)$ & $0.73(0.03)$ \\
Minor bleedings & $0.15(0.02)$ & $0.14(0.02)$ & $0.16(0.02)$ \\
Gastrointestinal complaints & $0.10(0.01)$ & $0.10(0.01)$ & $0.11(0.02)$ \\
Consistency ratio & 0.03 & 0.04 & 0.02 \\
Convenience & $N=43$ & $N=24$ & $N=19$ \\
Routine blood monitoring & $0.40(0.04)$ & $0.39(0.04)$ & $0.42(0.05)$ \\
Food restrictions & $0.27(0.03)$ & $0.27(0.04)$ & $0.28(0.05)$ \\
Intake frequency & $0.17(0.02)$ & $0.19(0.03)$ & $0.15(0.02)$ \\
Pill type/intake instruc- & $0.15(0.02)$ & $0.16(0.03)$ & $0.15(0.02)$ \\
$\quad$ tions & & & \\
Consistency ratio & 0.002 & 0.004 & 0.01 \\
\hline
\end{tabular}

All standard deviations were obtained by bootstrap analysis

$D O A C$ direct (non-VKA) oral anticoagulant, VKA vitamin $\mathrm{K}$ antagonist

In taking drugs for preventive purposes, the positive effects of OAC therapy lie in the future, while the side effects may impact patients today or on a daily basis. Thus, the frequency and severity of side effects were also very important to patients. Although the probability of experiencing a major bleeding with OAC therapy is low, the results of this study show that patients attach higher priority to reducing the frequency of major versus minor bleeds. One recommendation that would follow from this finding is to discuss both the probability and consequences of side effects with patients more explicitly, and to educate patients.

Compared to the efficacy and safety criteria, convenience was only of little importance to patients. Yet the available OACs only differ slightly in efficacy and safety rates, while the differences with regard to the attributes of convenience have a direct impact on patient's daily life. Moreover, our results show that patients have different preferences for options within the convenience criteria. Although most patients preferred once-daily intake, some patients preferred twice-daily intake (30\%) as they were used to this routine (e.g., taking the anticoagulants with breakfast and dinner). Furthermore, patients differed on the opinion whether routine INR monitoring is preferred to no monitoring. The qualitative focus group results showed that the perceived benefits of routine INR monitoring were related to reassurance, mainly resulting from the routine feedback on the effect of drugs and the contact with the doctor. Advocates of having no routine INR monitoring assume that routine blood monitoring results in being restricted in activities, having to make appointments at specific times and feeling anxious about the results [29]. Although only a few patients were bothered with having food restrictions, patients who have switched therapies (from VKA to DOAC) indicated that the food restrictions were a main reason for them to switch. Results have also shown that patients prefer simple intake instructions; requirements with regard to swallowing the pill as a whole or taking the pill with food lowered the performance value. Despite not being available on the market now, a melting pill was the second-most preferred type of pill. From this research, it is recommended that in clinical decision making, the differences in convenience should be discussed with the patient, it could be argued that drug prescriptions should follow patient preferences on this point.

Furthermore, convenience should always be balanced with (out-of-pocket) costs of the drug: DOACs are more expensive than warfarin. In most countries, patients do not directly pay these costs, although in Spain and France, patients pay part of the difference in actual drug costs. Obviously, paying higher out-of-pocket costs for DOACs reduce their overall value compared to warfarin, but in the focus groups, the costs of treatment were only of minor importance to focus group participants. None of the participants in these focus groups indicated that costs were a barrier to having the drugs they wanted.

This study had some limitations. First, the criteria that were included in the decision tree were chosen by the project team, based on the current literature and support of an international expert team. For example, a separate criterion for INR self-monitoring devices was not included, but whether patients use a self-monitoring device or visit the hospital might influence how patients perceive this need for regular INR monitoring. The structure of the value tree in MCDM is a recognized source of uncertainty, and its impact has been shown in literature $[31,32]$. Second, with regard to the method used to elicit preferences, the total number of comparisons that had to be made was high, which could influence patient concentration. The pairwise comparisons of the main hierarchy had a consistency ratio higher than 0.1 and was questioned last, so, fatigue may have played an important role. Third, we included a maximum of ten participants per country; therefore, it was not possible to focus on differences in importance weights across countries. Differences were mostly expected with regard to costs, and in all countries the importance of costs was rated low. However, whether actual differences in preferences exist between countries should be studied in a larger scale study. In addition, our sample of patients was relatively highly educated, which 
Table 3 Preferences and AHP performance weights for options within the convenience criteria

\begin{tabular}{|c|c|c|c|c|c|c|c|}
\hline \multirow[t]{2}{*}{ Intake frequency ${ }^{\mathrm{a}}$} & \multicolumn{2}{|l|}{ All patients $(n=45)$} & \multicolumn{2}{|c|}{ Once-daily takers $(n=33)$} & \multicolumn{2}{|c|}{ Twice-daily takers $(n=12)$} & \multirow[t]{2}{*}{ Chi square } \\
\hline & $N(\%)$ & Weight (SD) & $N(\%)$ & Weight (SD) & $N(\%)$ & Weight (SD) & \\
\hline Prefers once daily & $32(71.1)$ & $0.74(0.04)$ & $28(84.8)$ & $0.81(0.03)$ & $4(33.3)$ & $0.46(0.11)$ & 0.001 \\
\hline Prefers twice daily & $13(28.9)$ & $0.26(0.04)$ & $5(15.2)$ & $0.19(0.03)$ & $8(66.7)$ & $0.54(0.11)$ & \\
\hline \multirow[t]{2}{*}{ Routine INR monitoring ${ }^{\mathrm{a}}$} & \multicolumn{2}{|l|}{ All patients $(n=42)$} & \multicolumn{2}{|c|}{$\begin{array}{l}\text { VKA users (monitoring) } \\
(n=23)\end{array}$} & \multicolumn{2}{|c|}{$\begin{array}{l}\text { DOAC users (no monitoring) } \\
(n=19)\end{array}$} & Chi square \\
\hline & $N(\%)$ & Weight (SD) & $N(\%)$ & Weight (SD) & $N(\%)$ & Weight (SD) & \\
\hline Prefers monitoring & $17(37.8)$ & $0.49(0.05)$ & $13(56.6)$ & $0.57(0.08)$ & $4(21.1)$ & $0.39(0.06)$ & 0.14 \\
\hline Does not prefer monitoring & $17(37.8)$ & $0.51(0.05)$ & $8(34.8)$ & $0.43(0.08)$ & $9(47.4)$ & $0.61(0.06)$ & \\
\hline No preference & $8(17.8)$ & - & $2(8.7)$ & - & $6(31.6)$ & - & \\
\hline \multirow[t]{2}{*}{ Food restrictions ${ }^{\mathrm{b}}$} & \multicolumn{2}{|l|}{ All patients $(n=44), N(\%)$} & \multicolumn{2}{|c|}{$\begin{array}{l}\text { VKA users (restrictions) } \\
\quad(n=23), N(\%)\end{array}$} & \multicolumn{2}{|c|}{$\begin{array}{l}\text { DOAC users (no restrictions) } \\
\quad(n=19), N(\%)\end{array}$} & Chi square \\
\hline & $N(\%)$ & Weight (SD) & $N(\%)$ & Weight (SD) & $N(\%)$ & Weight (SD) & \\
\hline Not bothered & $34(75.6)$ & - & $21(84.0)$ & - & $13(68.4)$ & - & 0.22 \\
\hline Bothered & $10(22.2)$ & - & $4(16.0)$ & - & $6(31.6)$ & - & \\
\hline \multirow{2}{*}{$\begin{array}{l}\text { Pill type/intake } \\
\text { instructions }{ }^{c}\end{array}$} & \multicolumn{2}{|l|}{ All patients $(n=44)$} & & & & & \\
\hline & $N(\%)$ & Weight (SD) & & & & & \\
\hline $\begin{array}{l}\text { 1. Capsule, swallowed } \\
\text { whole, does not require } \\
\text { intake with food }\end{array}$ & $4(9.1)$ & $0.13(0.01)$ & & & & & \\
\hline $\begin{array}{l}\text { 2. Tablet, can be mixed } \\
\text { with water, does not } \\
\text { require intake with food }\end{array}$ & $16(36.4)$ & $0.33(0.03)$ & & & & & \\
\hline $\begin{array}{l}\text { 3. Tablet, can be mixed } \\
\text { with water, requires } \\
\text { intake with food }\end{array}$ & $5(11.4)$ & $0.25(0.03)$ & & & & & \\
\hline $\begin{array}{l}\text { 4. Tablet which dissolves } \\
\text { (melts) on the tongue, } \\
\text { and does not require } \\
\text { intake with food }\end{array}$ & $13(29.5)$ & $0.29(0.03)$ & & & & & \\
\hline 5. No preference & $6(13.6)$ & & & & & & \\
\hline
\end{tabular}

Data are presented as $N(\%)$ and AHP performance weight (SD)

$A H P$ analytic hierarchy process, DOAC direct (non-VKA) oral anticoagulant, INR international normalized ratio, $S D$ standard deviation, $V K A$ vitamin K antagonist

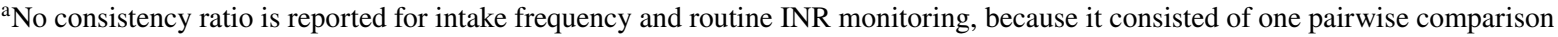

${ }^{b}$ No pairwise comparison was questioned to estimate performance, because it was likely that all patients would have a preference for not having food restrictions

${ }^{\mathrm{c}}$ The consistency ratio for pill type/intake instructions was 0.08

limits the generalizability of this study. Fourth, the pairwise comparisons were completed during the second hour of the focus groups. Although the focus group was led by experience moderators and open and semi-structured questions were used, patients with dominant views might have influenced the answers of other patients, or prompted them to give socially desirable answers [33]. Finally, it is clear that adherence is influenced by a large number of factors that are not related to the characteristics of the drug itself, such as knowledge and motivation of the patient. A broader model of adherence is required to understand and improve patient adherence to OACs.

\section{Conclusion}

Effectiveness and safety are the most important attributes of OAC therapy. Although the relative impact of convenience on therapy value is small, patients have different preferences for options within the convenience criteria. Besides considerations on safety and effectiveness, physicians should also discuss attributes of convenience with patients, as it can be assumed that alignment to patient preferences in drug prescription, and better patient education could result in higher adherence to treatment. The differences in individual preferences for convenience found within this study support the notion that decisions 
on which OAC therapy to take is a decision that has to be made with, and not for, the patient.

\section{Compliance with Ethical Standards}

Funding This study was funded by Daiichi Sankyo Europe GmbH (Munich, Germany). Besides the initial review process before funding and amendments, Daiichi Sankyo was only involved in the design of the study. The funders had no role in data collection and analysis, decision to publish, or the preparation of this manuscript.

Conflict of interest Marieke G.M. Weernink, Melissa C.W. Vaanholt, Catharina G.M. Groothuis-Oudshoorn, Clemens von Birgelen, Maarten J. IJzerman and Janine A. van Til declare that they have no conflicts of interest that might be relevant to the contents of this manuscript. In addition, $\mathrm{CvB}$ indicated non-related institutional research grants provided by several device-manufacturing companies.

Ethical approval All procedures performed in studies involving human participants were in accordance with the ethical standards of the institutional and/or national research committee and with the 1964 Helsinki declaration and its later amendments or comparable ethical standards. The study protocol, focus group guide and answer form were reviewed and approved by the institutional review board of the University of Twente.

Informed consent Informed consent was obtained from all individual participants included in the study.

Open Access This article is distributed under the terms of the Creative Commons Attribution-NonCommercial 4.0 International License (http://creativecommons.org/licenses/by-nc/4.0/), which permits any noncommercial use, distribution, and reproduction in any medium, provided you give appropriate credit to the original author(s) and the source, provide a link to the Creative Commons license, and indicate if changes were made.

\section{References}

1. Atrial Fibrillation Investigators. Risk factors for stroke and efficacy of antithrombotic therapy in atrial fibrillation. Analysis of pooled data from five randomized controlled trials. Arch Intern Med. 1994;154(13):1449-57.

2. Hart RG, Pearce LA, Aguilar MI. Meta-analysis: antithrombotic therapy to prevent stroke in patients who have nonvalvular atrial fibrillation. Ann Intern Med. 2007;146(12):857-67. https://doi. org/10.7326/0003-4819-146-12-200706190-00007.

3. Heidbuchel H, Verhamme P, Alings M, Antz M, Hacke W, Oldgren J, et al. European Heart Rhythm Association Practical Guide on the use of new oral anticoagulants in patients with non-valvular atrial fibrillation. Europace. 2013;15(5):625-51. https://doi. org/10.1093/europace/eut083.

4. Ruff CT, Giugliano RP, Braunwald E, Hoffman EB, Deenadayalu N, Ezekowitz MD, et al. Comparison of the efficacy and safety of new oral anticoagulants with warfarin in patients with atrial fibrillation: a meta-analysis of randomised trials. Lancet. 2014;383(9921):955-62. https://doi.org/10.1016/S0140 -6736(13)62343-0.

5. Connolly SJ, Ezekowitz MD, Yusuf S, Eikelboom J, Oldgren J, Parekh A, et al. Dabigatran versus warfarin in patients with atrial fibrillation. N Engl J Med. 2009;361(12):1139-51. https://doi. org/10.1056/NEJMoa0905561.

6. Giugliano RP, Ruff CT, Braunwald E, Murphy SA, Wiviott SD, Halperin JL, et al. Edoxaban versus warfarin in patients with atrial fibrillation. N Engl J Med. 2013;369(22):2093-104. https://doi. org/10.1056/NEJMoa1310907.

7. Granger CB, Alexander JH, McMurray JJV, Lopes RD, Hylek EM, Hanna M, et al. Apixaban versus warfarin in patients with atrial fibrillation. N Engl J Med. 2011;365(11):981-92. https:// doi.org/10.1056/NEJMoa1107039.

8. Patel MR, Mahaffey KW, Garg J, Pan G, Singer DE, Hacke W, et al. Rivaroxaban versus warfarin in nonvalvular atrial fibrillation. N Engl J Med. 2011;365(10):883-91. https://doi.org/10.1056/ NEJMoa1009638.

9. Brown TM, Siu K, Walker D, Pladevall-Vila M, Sander S, Mordin M. Development of a conceptual model of adherence to oral anticoagulants to reduce risk of stroke in patients with atrial fibrillation. J Manag Care Pharm. 2012;18(5):351-62. https:// doi.org/10.18553/jmcp.2012.18.5.351.

10. Bajorek BV, Ogle SJ, Duguid MJ, Shenfield GM, Krass I. Balancing risk versus benefit: the elderly patient's perspective on warfarin therapy. Pharm Pract. 2009;7(2):113-23.

11. Abdou JK, Auyeung V, Patel JP, Arya R. Adherence to long-term anticoagulation treatment, what is known and what the future might hold. Br J Haematol. 2016;174(1):30-42. https://doi. org/10.1111/bjh.14134.

12. Mekaj YH, Mekaj AY, Duci SB, Miftari EI. New oral anticoagulants: their advantages and disadvantages compared with vitamin $\mathrm{K}$ antagonists in the prevention and treatment of patients with thromboembolic events. Ther Clin Risk Manag. 2015;11:967-77. https://doi.org/10.2147/TCRM.S84210.

13. Ghijben P, Lancsar E, Zavarsek S. Preferences for oral anticoagulants in atrial fibrillation: a best-best discrete choice experiment. PharmacoEconomics. 2014;32(11):1115-27. https://doi. org/10.1007/s40273-014-0188-0.

14. Bottger B, Thate-Waschke IM, Bauersachs R, Kohlmann T, Wilke T. Preferences for anticoagulation therapy in atrial fibrillation: the patients' view. J Thromb Thrombolysis. 2015;40(4):406-15. https ://doi.org/10.1007/s11239-015-1263-x.

15. Najafzadeh M, Gagne JJ, Choudhry NK, Polinski JM, Avorn J, Schneeweiss SS. Patients' preferences in anticoagulant therapy: discrete choice experiment. Circ Cardiovasc Qual Outcomes. 2014;7(6):912-9. https://doi.org/10.1161/circoutcomes.114.00101 3.

16. Wilke T, Bauer S, Mueller S, Kohlmann T, Bauersachs R. Patient preferences for oral anticoagulation therapy in atrial fibrillation: a systematic literature review. Patient. 2017;10(1):17-37. https:// doi.org/10.1007/s40271-016-0185-9.

17. Laliberté F, Nelson WW, Lefebvre P, Schein JR, Rondeau-Leclaire J, Duh MS. Impact of daily dosing frequency on adherence to chronic medications among nonvalvular atrial fibrillation patients. Adv Ther. 2012;29(8):675-90. https://doi.org/10.1007/s1232 5-012-0040-x.

18. Saaty TL. The analytical hierarchy process, planning, priority. Chalfont St Peter: RWS; 1980.

19. Dolan JG. Shared decision-making-transferring research into practice: the analytic hierarchy process (AHP). Patient Educ Couns. 2008;73(3):418-25. https://doi.org/10.1016/j. pec.2008.07.032.

20. Keeney RL, Raiffa H. Decisions with multiple objectives: preferences and value trade-offs. Cambridge: Cambridge university; 1993.

21. Saaty T. Decision making with the analytic hierarchy process. Int J Serv Sci. 2008;1(1):83-98. 
22. Liberatore MJ, Nydick RL. The analytic hierarchy process in medical and health care decision making: a literature review. Eur J Oper Res. 2008;189(1):194-207.

23. Hummel JM, Bridges JF. Group decision making with the analytic hierarchy process in benefit-risk assessment a tutorial. Patient. 2014;7(2):129-40. https://doi.org/10.1007/s40271-014-0050-7.

24. Canada Thrombosis. Management of bleeding in patients who are receiving a new oral anticoagulant (dabigatran, rivaroxaban, apixaban). Canada: Thrombosis Canada; 2013.

25. Radner R, Rothschild M. On the allocation of effort. J Econ Theory. 1975;10(3):358-76. https://doi.org/10.1016/00220531(75)90006-X

26. Baik SH, Hernandez I, Zhang Y. Evaluating the initiation of novel oral anticoagulants in Medicare Beneficiaries. J Manag Care Spec Pharm. 2016;22(3):281-92. https://doi.org/10.18553 /jmcp.2016.22.3.281.

27. Tang KC, Davis A. Critical factors in the determination of focus group size. Fam Pract. 1995;12(4):474-5. https://doi.org/10.1093/ fampra/12.4.474.

28. Muhr R. ATLAS.ti Scientific software development GmbH. Berlin: $\mathrm{GmbH} ; 2004$.
29. Vaanholt MCW, Weernink MGM, Birgelen C, Groothuis-Oudshoorn CGM, Ijzerman MJ, Til JA. Perceived advantages and disadvantages of oral anticoagulants, and the trade-offs patients make in choosing anticoagulant therapy and adhering to their drug regimen. Patient Educ Couns. 2018. https://doi.org/10.1016/j. pec.2018.06.019.

30. Forman E, Peniwati K. Aggregating individual judgments and priorities with the analytic hierarchy process. Eur J Oper Res. 1998;108(1):165-9. https://doi.org/10.1016/S0377 -2217(97)00244-0.

31. Warren L. Uncertainties in the analytical hierarchy process (DSTO-GD-0356). Edinburgh, Australia: DSTO Information Sciences Laboratory; 2004. http://www.dtic.mil/dtic/tr/fulltext/ u2/a431022.pdf. Accessed 23 Nov 2017.

32. Paulson D, Zahir S. Consequences of uncertainty in the analytic hierarchy process: a simulation approach. Eur J Oper Res. 1995;87(1):45-56. https://doi.org/10.1016/0377-2217(94)00044 -D.

33. Acocella I. The focus groups in social research: advantages and disadvantages. Qual Quant. 2012;46(4):1125-36. 